\title{
ENSINO DE CIÊNCIAS POR INVESTIGACฺ̃̃: UMA ESTRATÉGIA PEDAGÓGICA PARA PROMOÇ̃̃O DA ALFABETIZAC̣ÃO CIENTÍFICA NOS PRIMEIROS ANOS DO ENSINO FUNDAMENTAL
}

Liliane Oliveira de Brito*

Elton Casado Fireman**

RESUMO: O presente estudo aponta o ensino de ciências por investigação como uma prática pedagógica que facilita a alfabetização científica nos primeiros anos do Ensino Fundamental. Para fazer o levantamento dos dados, uma sequência didática foi aplicada abordando a temática "De onde vem o arco-íris?". A pesquisa é de cunho qualitativo e do tipo pesquisa-ação e foi desenvolvida em um $5^{\circ}$ ano de Ensino Fundamental. Os resultados revelaram que os alunos, quando convidados a fazer investigações semelhantes às feitas pela cultura científica, desenvolvem conteúdos conceituais em um contexto dotado de significados. De tal modo, os alunos se tornam capazes de utilizar conceitos científicos como instrumentos de leitura, significação e compreensão do mundo, isto é, alfabetizamse cientificamente.

Palavras-chave: Ciências. Aprendizagem. Alfabetização científica. Ensino por investigação.

ENSEÑANZA DE LAS CIENCIAS POR INVESTIGACIÓN: UNA ESTRATEGIA PEDAGÓGICA PARA LA PROMOCIÓN DE LA ALFABETIZACIÓN CIENTÍFICA EN LOS PRIMEROS AÑOS DE LA PRIMARIA

RESUMEN: Esta investigación apunta la enseñanza de las ciencias por investigación como una práctica pedagógica que facilita la alfabetización científica en los primeros años de la Primaria. Para levantar los datos, una secuencia didáctica fue aplicada abordando la temática "De donde viene el arcoíris?". La investigación es cualitativa y del tipo investiga-acción y fue desarrollada en una clase del quinto año de la Primaria. Los resultados revelan que los alumnos, cuando invitados a hacer sus investigaciones semejantes a las hechas por la cultura científica, desarrollan contenidos conceptuales en un contexto lleno de significados. De tal manera, los alumnos se vuelven capaces de utilizar conceptos científicos como instrumentos de lectura, significación y comprensión del mundo, o sea, se alfabetizan científicamente.

Palabras clave: Ciencias. Aprendizaje. Alfabetización científica. Enseñanza por investigación.

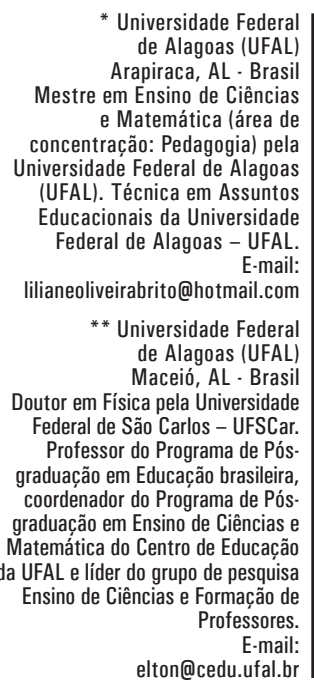

Universidade Federal Arapiraca, AL - Bras em Ensino de Ciências

e Matemática lárea de concentração: Pedagogia) pela Universidade Federal de Alagoas

(UFAL). Técnica em Assuntos ducacionais da Universidade Federal de Alagoas - UFAL.

Universidade Federa de Alagoas (UFAL) ceió, AL - Brasil Federal de São Carlos - UFSCar. Professor do Programa de Pósgraduação em Educação brasileira coordenador do Programa de Pós graduacão em Ensino de Ciências e Matemática do Centro de Educação UFAL e líder do grupo de pesquisa E-mail: elton@cedu.ufal.br 


\section{RESEARCH IN SCIENCE EDUCATION: AN EDUCATIONAL STRATEGY TO PROMOTE SCIENTIFIC LITERACY IN PRIMARY EDUCATION'S FIRST YEAR}

ABSTRACT: This study defends science teaching by research as a pedagogical practice that facilitates scientific literacy in primary school's first years. To collect data, a didactic sequence was applied addressing the theme "Where does the rainbow come from?" The research is qualitative and of the action-research kind. It was developed in a primary school's 5 th year class. The results revealed that students develop conceptual contents in a context endowed with meaning when invited to do research similarly to those made by the scientific culture. In this way, students become able to use scientific concepts such as reading instruments, meaning and understanding of the world, which means they become scientifically literate.

Keywords: Science. Learning. Literacy. Scientific literacy. Teaching by research. 


\section{INTRODUÇÃO}

O debate sobre a alfabetização científica é bastante presente no ensino de ciências, mesmo assim, a ideia sobre o assunto apresenta controvérsias em sua definição. Por esse motivo, Sasseron e Carvalho (2008) identificaram três eixos estruturantes que servem de apoio aos planejamentos de ensino que têm como foco alfabetizar cientificamente os alunos. O primeiro eixo se refere à compreensão básica de termos, conhecimentos e conceitos científicos fundamentais, o segundo se refere à compreensão da natureza da ciência e dos fatores éticos e políticos que circundam sua prática e o terceiro se refere ao entendimento das relações existentes entre ciência, tecnologia e sociedade.

Com foco no primeiro eixo citado por Sasseron e Carvalho (2008), passamos a assumir a alfabetização científica como uma meta que visa conduzir o aluno a compreender conceitos científicos de forma a significá-los em suas vivencias cotidianas. Nesses termos, a ideia é possibilitar aos alunos a compreensão da linguagem da ciência para que sejam capazes de ampliar o universo de conhecimento sobre o mundo de forma consciente.

Por se tratar de uma meta, para ser alcançada, a alfabetização científica demanda práticas pedagógicas que viabilizem seus objetivos. De tal modo, nessa pesquisa partimos do pressuposto de que o ensino de ciências por investigação que é uma metodologia de ensino que visa aproximar o aluno do "fazer ciência" dos verdadeiros cientistas, por meio da resolução de problemas reais com espaço e tempo para questionamentos, testes de hipóteses, trocas de informações e sistematizações de ideias - pode servir de maneira eficaz para alfabetizar cientificamente alunos dos anos iniciais.

Nesses termos, o problema que deu origem a esta pesquisa foi assim formulado: o ensino de ciências por investigação, com seus referencias teóricos e práticos, se constituiu como uma estratégia metodológica eficiente para promoção da alfabetização científica nos primeiros anos do Ensino Fundamental?

Para responder a essa questão foi aplicada uma sequência didática intitulada "De onde vem o arco-íris?" com alunos de um $5^{\circ}$ ano de Ensino Fundamental. Os dados aqui apresentados nos autorizam a afirmar que os alunos dos anos iniciais, quando convidados a trabalhar os conteúdos de ciências dentro de investigações semelhantes às feitas nos laboratórios de pesquisa, passam a desenvolver habilidades que lhes permitem dominar a linguagem da ciência, de modo a fazer dela um instrumento de interpretação e significação do mundo, em outras palavras, alfabetizam-se cientificamente.

Principais pressupostos da alfabetização científica

Ao nos debruçarmos na literatura que discute os conceitos e os objetivos da alfabetização científica, percebemos que há controvérsias em sua definição. Nesses termos, Shen (1975), citado por Lorenzetti e Delizoicov (2000), afirma que a alfabetização científica pode significar muitas coisas, "[...] desde saber como preparar uma refeição nutritiva, até saber apreciar as leis da física” (SHEN, 1975 citado por LORENZETTTI; DELIZOICOV, 2000, p. 3, tradução dos autores).

$\mathrm{Na}$ literatura nacional encontramos autores como Zimmermann (2005) que usam o termo "Letramento Científico". Esse entendimento do assunto possui 
origem nas ideias de Soares (2004), quando afirma que o letramento visa desenvolver no educando habilidades para retirar significados da leitura e da escrita no sentido de fazer uso compreensivo das informações veiculadas na sociedade. Embasado nesse entendimento, o letramento científico passa a se referir " [...] ao uso do conhecimento científico e tecnológico no cotidiano, no interior de um contexto sócio-histórico específico" (ZIMMERMANN, 2005, p. 2).

Nessa perspectiva, também encontramos autores como Lorenzetti e Delizoicov (2000) que tratam o assunto com o termo "alfabetização científica". Os autores definem que a alfabetização científica é um processo pelo qual a ciência se constitui como uma linguagem que oportuniza aos alunos significar os assuntos científicos de modo que possam ampliar a sua cultura.

Há, ainda, pesquisadores como Carvalho (2013) que utilizam a expressão "enculturação científica" na premissa de que a Educação, além de promover a cultura religiosa, social e histórica, também deve promover uma cultura científica, que, entre outros aspectos, permita aos alunos "[...] trabalhar e discutir problemas envolvendo fenômenos naturais como forma de introduzi-los ao universo das ciências" (SASSERON; CARVALHO 2007, p. 2).

Demo (2010) fez uma análise sobre a alfabetização científica, no sentido de mostrar que as novas alfabetizações demandadas no século XXI ultrapassam as habilidades propostas para alfabetização tradicional (ler, contar e escrever), pois a exigência atual é marcada pela formação científica como forma de inserção na sociedade do conhecimento. $\mathrm{O}$ autor enfatiza que para essa formação científica acontecer, exitosamente, deve-se colocar a atividade de pesquisa como ação precípua nas práticas curriculares da escola básica e da Universidade, ou seja, deve-se "[...] educar pela pesquisa [...]" (DEMO, 2010, p. 54).

Para Chassot (2000), a ciência deve ser vista como uma linguagem, que possibilita ao homem explicar o mundo natural. Sendo assim, as incompreensões que uma pessoa ao ler um texto em português apresenta podem ser comparadas às incompreensões que uma pessoa possui ao não dominar a linguagem da ciência, isto é, quem não domina a linguagem científica passa a não saber ler aquilo em que está escrita a natureza, logo, passa a não entender significativamente o mundo natural em que vive.

É perceptível que a alfabetização científica é marcada por discussões diversas, mas os principais estudos sobre o tema convergem basicamente para o entendimento de três aspectos, conforme definem Sasseron e Carvalho (2008, p. 335):

[...] a compreensão básica de termos e conceitos científicos fundamentais, a compreensão da natureza da ciência e dos fatores éticos e políticos que circundam sua prática e o entendimento das relações existentes entre ciência, tecnologia, sociedade e meio ambiente.

Assim, estando entre os três pontos o entendimento da alfabetização científica como a compreensão básica de termos e conceitos científicos fundamentais (SASSERON; CARVALHO, 2008), passamos, neste trabalho, a assumir a alfabetização científica sob a ótica de possibilitar ao aluno o conhecimento do mundo natural por meio da compreensão de conceitos científicos, de forma que ele possa ter uma visão de mundo mais consciente. 
Para alcançarmos esse objetivo, acreditamos ser necessário levar para sala de aula problemas envolvendo fenômenos naturais que incitem os alunos a investigação por meio de análises críticas. Tais análises podem ser alcançadas pela prática das seguintes ações: formulações de hipóteses, testes de hipóteses, comparação de evidências, troca de experiências, argumentação e socialização das conclusões alcançadas.

\section{MODELO DE MUDANÇA CONCEITUAL E SUAS IMPLICAÇÕES NO PROCESSO DE ALFA- BETIZAÇÃO CIENTÍFICA}

Visto que propomos a alfabetização científica sob a ótica de conduzir o aluno a aprender significativamente conceitos científicos como instrumento de compreensão do mundo natural, cabe aqui discutir, mesmo que de forma breve, alguns aspectos acerca do modelo de mudança conceitual.

Cabe pontuar que na década de 1960 surgiu um modelo pedagógico que ficou conhecido como "ensino por redescoberta". Nessa perspectiva, o ensino do método científico, envolvido na construção do conhecimento, passou a ser enfatizado nas práticas pedagógicas. Apesar de o ensino por redescoberta ter aproximado o aluno para atividade científica e oportunizado o estudo da história das ciências, ele se constituiu como uma prática de ensino equivocada, pois se acreditava que, por meio de um método rígido baseado em atividades de observação, experimentação e generalização, semelhantes às dos cientistas, os alunos atingiriam evidências, tendo de formular novas hipóteses aos fenômenos observados.

De acordo com Campos e Nigro (1999), o ensino por redescoberta difundiu a necessidade de oportunizar aos alunos a realização de um método científico em sala de aula. Esse método era pautado no seguinte pressuposto: ao passo que os alunos observassem e generalizassem resultados por meio da observação experimental, eles iriam, consequentemente, deparar-se com evidências científicas que os impulsionariam a formular hipóteses mais alinhadas ao entendimento científico do fenômeno em estudo.

Após algumas tentativas do uso do ensino de ciências por redescoberta em sala de aula, foi debatida, na didática em ciências, a ideia de que “[...] os alunos viam os fatos e os fenômenos da natureza de uma forma muito peculiar, geralmente distinta do conhecimento científico formal" (CAMPOS; NIGRO, 1999, p. 27).

Foi nessa perspectiva, que, na década de 1980, começaram a surgir várias pesquisas argumentando que os alunos possuíam uma maneira bastante própria de interpretar os fenômenos da natureza, e que essas formas de interpretação, geralmente, destoavam das formas de caracterização dos conhecimentos científicos. Esses estudos também alegaram que essas interpretações, que pareciam bastante intrínsecas aos alunos, eram de natureza intuitiva desconhecida, fato que as tornavam bastante resistentes ao ensino formal (SILVA; SILVA; BELTRAN NUÑES, 2004).

Para Pozo e Crespo (2009) essas interpretações, que são os conhecimentos prévios $^{1}$, são concepções generalizantes de caráter bastante singular, implícitas e de difícil verbalização. Por possuir essas características, nem sempre as ativações dos conhecimentos prévios vão confluir para o objetivo principal da teoria significativa da aprendizagem, que é justamente levar o aluno, diante de uma informação nova, a buscar em seu aparato cognitivo conhecimentos prévios para significar a 
informação, transformando suas concepções iniciais em um conhecimento novo. Referindo-se às concepções alternativas na aprendizagem dos conteúdos de ciências, também argumentam Campos e Nigro (1999, p. 83):

O que parece ocorrer é que os alunos criam um significado para as informações a que têm acesso, adaptando-as às suas próprias concepções. Desse modo, acabam criando uma realidade própria, que dá sentido à informação que receberam, sem, no entanto, alterar a sua concepção inicial.

Assim, apesar de os alunos vivenciarem o conhecimento formal na escola durante anos, muitos não conseguem abandonar suas concepções alternativas de entendimento do mundo. Essa situação acontece, entre outros fatos, em virtude dessas concepções se constituírem como conhecimentos que possuem uma organização única e pessoal, questão que as tornam resistentes às mudanças.

A premissa de que a ativação dos conhecimentos prévios é importante, mas nem sempre suficiente para desencadear novas aprendizagens, trouxe novos objetivos ao ensino de ciências. Esses novos objetivos convergiram para uma orientação didática, que ficou conhecida como conflito cognitivo e mudança conceitual. Nessa perspectiva, a mudança conceitual é consequência de um conflito cognitivo e, assim, a elaboração de propostas de ensino sob essa concepção demanda situações que deflagrem, nos estudantes, a sensação de conflitos a resolver.

Nessa perspectiva, Campos e Nigro (1999) esclarecem que umas das orientações didáticas para ocasionar o conflito cognitivo e, consequentemente, a mudança conceitual, foi, basicamente, colocar o aluno diante de várias situações que evidenciassem um contrassenso entre as ocorrências reais dos fenômenos e as suas concepções.

Com essas atividades, esperava-se que o aluno percebesse as discrepâncias entre a ocorrência do fenômeno e suas ideias iniciais, não encontrando, por isso, bases sólidas que continuassem sustentando seu modelo explicativo. De tal modo, o que se esperava era que o aluno abandonasse explicações guiadas por suas concepções prévias, dando lugar a explicações guiadas pela ciência. Vejamos em Campos e Nigro (1999, p. 27) uma atividade prática visando esse objetivo.

[...] se um aluno acredita que o efeito de afundar é determinado pelo volume de um objeto - objetos grandes afundam e objetos pequenos flutuam -, e não pela relação entre a sua massa e o seu volume, o professor pode, então, criar situações nas quais esse sistema explicativo não seja válido. Uma das possibilidades seria apresentar ao aluno dois objetos: um pequeno e bem denso e um grande e pouco denso. Em seguida, o professor poderia perguntar ao aluno o que ele acha que irá acontecer se os objetos forem mergulhados na água. Caso o aluno diga que o objeto maior vai afundar e o menor não, ele estará em situação de conflito cognitivo ao observar o resultado da atividade.

Contudo, a literatura em didática em ciências aponta que a prática para o conflito cognitivo se mostrou insuficiente para ocasionar a mudança de conceitos. Essa situação ocorreu, em grande medida, pelo fato de os alunos, mesmo diante de evidências empíricas, não conseguirem perceber incoerências 
entre essas experiências e suas concepções iniciais, não alcançando, por isso, a almejada mudança de conceitos.

Pozo e Crespo (2009, p. 89) nos dizem que as concepções alternativas não são um problema a mais para o processo de ensino e aprendizagem. A questão reside na prática pedagógica, pois, na maioria das vezes, o docente se limita a ensinar conceitos, não oportunizando, por isso, conduzir o aluno a uma mudança de atitudes em relação à ciência.

Por esse motivo, acreditamos que, para iniciar o processo de mudança conceitual, é essencial que o professor propicie um ambiente encorajador para que os alunos se envolvam efetivamente com o fenômeno em estudo. Isso significa que o docente deve propor problemas investigativos, que não se limitem a situar o aluno como um expectador de aulas. Nesse contexto, é necessário disponibilizar tempo e espaço para que os alunos argumentem sobre os fenômenos estudados, que reflitam sobre suas afirmações, que construam conclusões pela troca de experiências no grupo, que adquiram o hábito de trabalhar com refutações até chegar à evolução dos conceitos envolvidos no fenômeno.

Nessa perspectiva, partimos do pressuposto de que o ensino por investigação, por ocasionar uma mudança de atitude do aluno com a ciência, se constitui em uma metodologia de ensino que o ajuda a evoluir em seus sistemas explicativos pautados pelas concepções alternativas, pois uma metodologia investigativa pode propiciar ao aluno segurança no envolvimento com práticas científicas, de modo que o leve a resolver uma situação problema de forma não superficial.

Nesses termos, o aluno não somente "faz ciência", mas também aprende "sobre ciências". O aluno não somente aprende conceitos pela argumentação e pelo exercício da razão, mas aprende a discutir e a emitir juízo de valor aos conteúdos estudados. Em decorrência disso, ele passa a compreender os fenômenos do mundo natural, de maneira que se torna capaz de fazer uma leitura de mundo mais consciente, isto é, se alfabetiza cientificamente.

\section{ENSINO DE CIÊNCIAS POR INVESTIGAC̣ÃO: PENSANDO PROCESSOS DE ENSINO PARA VIABILIDADE DA ALFABETIZAÇ̃̃O CIENTÍFICA NOS PRIMEIROS ANOS DO ENSINO FUNDAMENTAL}

Cachapuz (2005) afirma que há a necessidade de ocorrer uma renovação na educação científica, mas que, para tanto, faz-se necessário sucumbir com visões deformadas da ciência e tecnologia. Segundo o autor, entre essas visões existe a ideia arraigada entre os alunos de que a ciência é uma área do saber reservada a gênios em seus sofisticados laboratórios, bem como é um conhecimento detentor de verdades absolutas e inexoráveis.

Segundo, ainda, Cachapuz (2005), essas visões acerca da ciência são distorcidas e podem se constituir como um empecilho para que os alunos se interessem por assuntos científicos. Nessa perspectiva, Briccia (2013) vê na ideia do "fazer ciência" uma maneira de romper com essas visões que geralmente são repassadas pelas práticas tradicionais de ensino. Para a autora, esse "fazer ciência" se constitui como estratégia para trabalhar aspectos da natureza da ciência de maneira implícita na metodologia de ensino do professor. Assim, exemplificando, o professor pode 
propor em sala de aula uma situação problema para ser investigada pelos alunos e oportunizar tempo e espaço para que elaborem hipóteses, testem essas hipóteses, observem variáveis, discutam e interpretem resultados, bem como socializem de forma argumentativa as ideias que concluíram.

Como se pode perceber, essas ações se tratam de práticas pertencentes à cultura científica. Desse modo, o que se propõe é que as características epistemológicas, ou de construção do conhecimento científico, sejam trabalhadas didaticamente no ensino de ciências por meio de processos investigativos das temáticas abordadas em sala de aula. Acerca dessa proposta, vejamos o que nos diz Briccia (2013, p. 118, grifo nosso):

Acreditamos que a metodologia utilizada pelo docente na condução do seu trabalho traz, mesmo que implicitamente, características da Natureza das Ciências. Ao conduzir situações de aprendizagens, ao criar um ambiente propício para o ensino, também se ensina sobre Ciências e não apenas sobre aspectos conceituais. Uma metodologia investigativa, por exemplo, pode ressaltar o caráter investigativo do conhecimento científico, além de outros aspectos. Portanto, a metodologia do trabalho utilizado pelo docente também é conteúdo.

É com essa ideia (de que a metodologia também ensina) que passamos a vislumbrar o ensino de ciências por investigação como uma prática que, por meio do ensinar "sobre ciência", bem como do "fazer ciência", possibilita ao aluno se alfabetizar cientificamente. Tal pressuposto emerge dos referenciais teóricos estudados, que nos afirmam que essa prática de ensino possibilita aos alunos, por meio do exercício da investigação, refletir e argumentar sobre os elementos envolvidos nos fenômenos a partir de uma análise crítica.

\section{SEQUÊNCIA DIDÁTICA PLANEJADA PARA VIABILIZAC̣ÃO DA ALFABETIZAC̣ÃO CIENTÍFICA: DISCUTINDO ACÕES PRÁTICAS DENTRO DA PROPOSTA DO ENSINO DE CIÊNCIAS POR INVESTIGAÇÃ́O}

Carvalho (1998) se destaca na literatura de ciências como autora que divulga a necessidade de o professor conduzir as crianças a discutirem os fenômenos físicos que as cercam. O objetivo é orientar os alunos dos primeiros anos escolares a construir, com seus referenciais lógicos, significados do mundo natural.

Esse processo, vislumbrado na perspectiva da alfabetização científica, deve ser pensado sob a ótica da realização de diversas práticas que abordem atividades capazes de oportunizar a resolução de problemas por meio do diálogo, da ação do aluno, do convite ao pensar científico, da argumentação, do refletir, do analisar resultados. Essas ações devem levar, por consequência, à introdução de conceitos.

Diante dessas assertivas, planejamos uma sequência didática nos aportes teóricos e práticos do ensino de ciências por investigação pensados por Carvalho (1998; 2013). O objetivo foi utilizar esse planejamento como instrumento para averiguar o problema da pesquisa, ou seja, verificar se o ensino de ciências por investigação se constitui como metodologia de ensino eficaz para promoção da alfabetização científica nos anos iniciais. Vejamos no Quadro 1 a sequência didática proposta. 
Quadro 1 - Sequência didática: “De onde vem 0 arco-íris?"

\section{SEQUÊNCIA DIDÁTICA: “DE ONDE VEM O ARCO-ÍRIS?”}

Objetivos gerais:

Utilizar conceitos científicos básicos para explicação da ocorrência do arco-íris; Desenvolver o hábito de observar, pensar o observado e indagar questões a respeito dos fenômenos naturais;

Entender a ocorrência do arco-íris pelo viés científico;

Entender de forma significativa as causas e efeitos do arco-íris;

Desenvolver a leitura e a escrita por meio dos conteúdos de ciências;

Aprender ciências de maneira prazerosa por meio das imagens e dos sons lúdicos veiculados nos vídeos da série "De onde vem?";

Aprofundar conceitos envolvidos no fenômeno do arco-íris por meio do vídeo da série "De onde vem?";

Pesquisar e realizar atividades de experimentação;

Organizar e registrar informações por meio de desenhos e pequenos textos;

Utilizar a ciência como instrumento de descoberta do mundo.

Série: $5^{\circ}$ ano do Ensino Fundamental

Conteúdo: De onde vem o arco-íris?

Tempo estimado: duas aulas com duração de quatro horas cada uma.

Material necessário: vídeos da série "De onde vem o arco-íris?", lápis de cor, papel ofício, cartolina, lanterna, água, ventilador, vasilha de plástico, CD.

0 aluno com essa aula poderá: compreender que o arco-íris é formado quando existe a presença de água e luz solar; ampliar o vocabulário mediante o entendimento do conceito de refração; verificar e compreender a formação da luz branca por meio de experimentos; compreender de maneira implícita os procedimentos da prática científica; perceber a ciência em sua vida cotidiana, utilizando-a como instrumento de significação do mundo; aprender a trabalhar coletivamente; desenvolver competências e habilidades referentes à alfabetização científica.

1a AULA

1a ETAPA - FORMAC̣ÃO DO ARCO-ÍRIS

$1{ }^{\circ}$ MOMENTO: VERIFICANDO O CONHECIMENTO INICIAL SOBRE 0 ASSUNTO

Utilizando um projetor, ou figuras retiradas da internet, apresentar a figura de um arco-íris para os alunos e explanar a questão: um efeito luminoso misterioso, cercado por vários mitos. Afinal, quando o arco-íris aparece no céu? Quais são as cores que ele tem? Por que o arco-íris aparece no céu?;

Atentar para as perguntas como e por que acontece;

Depois de escutar as hipóteses dos alunos, entregar uma folha de papel oficio e solicitar que escrevam essas hipóteses, bem como desenhem e pintem o arco-íris. 


\section{$2^{\circ}$ MOMENTO: PROPONDO O PROBLEMA}

Propor a seguinte demonstração investigativa: colocar um recipiente de plástico transparente em frente a uma parede, uma cartolina ou um quadro branco. Mostrar aos alunos uma lanterna e propor o seguinte problema: como fazer para que um arco-íris apareça no quadro branco utilizando esses materiais? Para ver esse experimento: <www.youtube. com/watch?v=9pCOJXJOVE0>.

\section{$3^{\circ}$ MOMENTO: AGINDO SOBRE OS OBJETOS PARA VER COMO ELES REAGEM}

Escutar atentamente as hipóteses dos alunos, testando-as para obter o efeito desejado, ou seja, projetar a imagem de um arco-íris no quadro branco.

\section{$4^{\circ}$ MOMENTO: TOMANDO CONSCIÊNCIA DE COMO FOI PRODUZIDO O EFEITO DESEJADO}

Depois de conseguir o efeito desejado, guardar os objetos utilizados;

Reunir os alunos em um semicírculo ou colocá-los sentados no chão;

Lançar os seguintes questionamentos: quais foram as cores que vimos na parede? São as mesmas do arco-íris? Como conseguimos fazer a imagem do arco-íris aparecer no quadro branco?;

Motivar os alunos a expressar as ações feitas no experimento;

Escutar com entusiasmo os relatos dos alunos;

Orientar os alunos para que esperem a sua vez de falar.

\section{$5^{\circ}$ MOMENTO: DANDO AS EXPLICAC̣̃̃ES CAUSAIS}

Por que a imagem do arco-íris apareceu no quadro branco? Podemos comparar a luz branca da lanterna com a luz do sol? Por quê? E a água na vasilha, podemos compará-la com as gotinhas de água suspensas no ar depois de uma chuva?

\section{$6^{\circ}$ MOMENTO: APROFUNDANDO A APRENDIZAGEM}

Como forma de sistematização e aprofundamento do conteúdo, assistir a primeira² parte do vídeo "De onde vem o arco-íris?";

Como forma de contextualização social do conteúdo, ler coletivamente a primeira ${ }^{3}$ parte do texto: "0 segredo do arco-íris"; disponível em: <http://www.ufal.edu.br/ppgecim/dissertacoes/dissertacoes-2014/ensino-de-ciencias-por-investigacao-uma-estrategia-pedagogica-para-promocao-da-alfabetizacao-cientifica-nos-primeiros-anos-do-ensino-fundamental> (ver apêndice 4);

Após a leitura coletiva do texto " 0 segredo do arco-íris", fazer os seguintes questionamentos: o que acontece quando a luz do sol atravessa uma gota de água após a chuva?;

0 que é refração?;

Solicitar aos alunos que façam um texto com ilustrações explicando por que a demonstração investigativa deu certo. 


\begin{tabular}{|l|}
\hline \multicolumn{1}{|c|}{$2^{\circ}$ ETAPA - COMPOSIÇÃO DA LUZ BRANCA } \\
\hline $1{ }^{\circ}$ MOMENTO: VERIFICANDO O CONHECIMENTO INICIAL SOBRE O ASSUNTO \\
Um homem chamado Isaac Newton fez um experimento: em seu quarto pegou um prisma, que \\
é um objeto transparente com vários lados e o colocou em frente à janela do seu quarto. Ele \\
abriu uma pequena parte da janela e verificou que quando os raios do sol atravessavam o pris- \\
ma uma faixa colorida aparecia na parede. Diante dessa situação, ele pensou: por que será \\
que quando a luz do sol atravessa o prisma a cor branca se divide em várias cores? Com essa \\
questão, Newton teve a seguinte ideia: experimentar pintar um disco com as cores vermelha, \\
amarela, laranja, azul, azul anil e violeta. Esse disco ficou conhecido como disco de Newton. \\
Isso feito, Newton experimentou fazer o disco girar o mais rápido possível. 0 que será que \\
aconteceu? \\
Escutar atentamente as hipóteses dos alunos.
\end{tabular}

\section{$2^{\circ}$ MOMENTO: PROPONDO O PROBLEMA}

Temos aqui um ventilador e um disco de Newton. Como fazer o disco girar o mais rápido possível usando esses materiais? 0 que será que acontecerá quando o disco girar rapidamente?

$3^{\circ}$ MOMENTO: AGINDO SOBRE OS OBJETOS PARA VER COMO ELES REAGEM

Escutar as hipóteses dos alunos e testá-las no objetivo de obter o efeito desejado.

$4^{\circ}$ MOMENTO: TOMANDO CONSCIÊNCIA DE COMO FOI PRODUZIDO O EFEITO DESEJADO

Terminada a demonstração investigativa, guardar os materiais utilizados;

Reunir os alunos em um semicírculo ou colocá-los sentados no chão;

Fazer as seguintes indagações: como conseguimos resolver o problema?;

Motivar os alunos a expressar as ações feitas no experimento;

Escutar com entusiasmo os relatos dos alunos;

Orientar os alunos para que esperem a sua vez de falar.

\section{$5^{\circ}$ MOMENTO: DANDO AS EXPLICAC̣̃̃ES CAUSAIS}

0 que aconteceu quando ligamos o ventilador?;

Por que ao ligarmos o ventilador enxergamos o disco branco?.

$6^{\circ}$ MOMENTO: APROFUNDANDO A APRENDIZAGEM

Como forma de sistematização do conteúdo, assistir ao vídeo completo "De onde vem o arco-íris?", disponível em:<www.youtube.com/watch?v=DbMigMVlOCc>;

Lançar as seguintes perguntas: por que a mãe da Kika disse que o arco-íris vinha da água da mangueira? Por que quando giramos o disco de Newton passamos a enxergá-lo branco?;

Como forma de contextualização social do conteúdo trabalhado, fazer a leitura coletiva da segunda parte do texto "0 segredo do arco-íris";

Lançar as seguintes questões: igualmente a Kika e seus amigos, vocês já viram um arco-íris? Onde vocês estavam quando viram esse fenômeno da natureza? Quando vocês viram o arco-íris, como estava o tempo? Chuvoso, nublado ou ensolarado?;

Entregar uma atividade para que os alunos registrem por meio de desenhos e da escrita o que aprenderam com a demonstração investigativa trabalhada. 
Como se pode perceber, a referida sequência didática é constituída por duas etapas contendo seis momentos cada uma e aborda conteúdos de natureza física. Na primeira etapa, trabalhamos o conteúdo "formação do arco-íris" com o objetivo de conduzir os alunos a compreender de forma significativa o processo da refração. Já no segundo momento, trabalhamos a "composição da luz branca" com o intuito de levar os discentes a melhor ressignificar a aprendizagem dos conceitos envolvidos no fenômeno do arco-íris.

Vejamos no Quadro 2, logo abaixo, os objetivos de cada momento proposto na sequência didática "De onde vem o arco-1́ris?"

Quadro 2 - Objetivos de cada momento proposto na sequência didática "De onde vem 0 arco-íris?"

\begin{tabular}{|l|l|l|}
\hline \multicolumn{1}{|c|}{ MOMENTOS } & \multicolumn{1}{|c|}{ PROPOSTA DE TRABALHO } & \multicolumn{1}{c|}{ OBJETIVOS } \\
\hline Primeiro momento & $\begin{array}{l}\text { Verificando o conhecimento } \\
\text { inicial sobre o assunto. }\end{array}$ & $\begin{array}{l}\text { Verificar as ideias prévias que os alunos } \\
\text { possuem sobre o conteúdo. }\end{array}$ \\
\hline Segundo momento & Propondo o problema. & $\begin{array}{l}\text { Apresentar o material experimental, bem } \\
\text { como explanar a situação a ser resolvida. }\end{array}$ \\
\hline Terceiro momento & $\begin{array}{l}\text { Agindo sobre os objetos } \\
\text { para ver como eles reagem. }\end{array}$ & $\begin{array}{l}\text { Oferecer tempo para pensar no problema } \\
\text { edesenvolver hipóteses levando-as ao } \\
\text { teste. }\end{array}$ \\
\hline Quarto momento & $\begin{array}{l}\text { Tomando consciência de } \\
\text { como foi produzido o efeito } \\
\text { desejado. }\end{array}$ & $\begin{array}{l}\text { Conduzir o aluno a pensar nas ações que } \\
\text { realizou, ou seja, a passar da ação mani- } \\
\text { pulativa para ação intelectual. }\end{array}$ \\
\hline Quinto momento & $\begin{array}{l}\text { Dando explicações causais. } \\
\text { Sexto momento }\end{array}$ & $\begin{array}{l}\text { Desenvolver a construção de conceitos e } \\
\text { a ampliar o vocabulário por meio de ex- } \\
\text { plicações. }\end{array}$ \\
\hline mento. & $\begin{array}{l}\text { Levar o aluno a pensar e a entender as } \\
\text { ações e os efeitos causais envolvidos no } \\
\text { experimento com uma linguagem mais } \\
\text { formal. }\end{array}$ \\
\hline
\end{tabular}

\section{METODOLOGIA DE PESQUISA: CARACTERIZAÇÃO DOS INSTRUMENTOS DE INVESTIGAÇ̃̃O}

Realizamos a presente pesquisa sob os fundamentos da abordagem qualitativa, pois essa forma de trabalho "[...] tem por objetivo expressar o sentido dos fenômenos do mundo social” (NEVES, 1996, p. 1). A pesquisa bibliográfica foi realizada “[...] 
a partir do registro disponível, decorrente de pesquisas anteriores, em documentos impressos, como livros, artigos, teses etc." (SEVERINO, 2007, p. 122).

Como modalidade de pesquisa, optamos pelo estudo de caso, pois esse "[...] se concentra no estudo de um caso particular, considerado representativo de um conjunto de casos análogos, por ele significativamente representativo" (SEVERINO, 2007, p. 121). Com essa definição, controlamos o campo de atuação da presente investigação escolhendo um caso particular para estudá-lo. Desse modo, com base na pesquisa-ação, assumimos uma postura ativa no envolvimento com os sujeitos investigados. Esse posicionamento foi tomado com o objetivo de não somente compreender o contexto, as consequências e as causas do fenômeno em estudo, mas também de possibilitar a transformação de uma condição inicial, averiguando sob quais bases isso seria plausível.

Os pesquisadores, no decorrer da investigação, agiram como observadores participantes. Esse tipo de atuação [...] "consiste na participação real do pesquisador. Ele se incorpora ao grupo, confunde-se com ele. Fica tão próximo quanto um membro do grupo que está estudando e participa das atividades normais deste" (MARCONI; LAKATOS, 2006, p. 90).

Assim, atuando como pesquisadores participantes, os investigadores da presente pesquisa ministraram a sequência didática "De onde vem o arco-íris?" para 18 alunos, durante dois dias, em uma turma do $5^{\circ}$ ano do Ensino Fundamental de uma Escola municipal, na cidade de Palmeira dos Índios - AL. Nessa perspectiva, como técnica de coleta dos dados, foi feito o uso de questionários com perguntas abertas, bem como o uso de gravações em áudio durante todo o desenrolar das aulas.

Optamos pela análise de conteúdo como procedimento de interpretação dos dados coletados. Para apresentar os dados dessa pesquisa, fizemos as transcrições das falas dos pesquisados durante o desenrolar das aulas. Nesse sentido, guiados principalmente pelos pressupostos teóricos do ensino de ciências por investigação, delineados por Carvalho et al. (1998), bem como pelos fundamentos do livro "Ensino de ciências por investigação: condições para implementação em sala de aula" de Carvalho (2013), procuramos, de forma sistematizada, realizar uma leitura e interpretação tanto da escrita, quanto da fala dos sujeitos envolvidos na pesquisa.

Assim, considerando-se que “[...] a intenção da análise de conteúdo é a inferência de conhecimentos relativos às condições de produção [...]" (BARDIN, 2011, p. 44), aproveitamos a escrita e a fala dos sujeitos pesquisados para verificar se as orientações da sequência didática conduziram os alunos a apresentar elementos que nos indicassem se o ensino de ciências por investigação se constitui como uma prática de ensino plausível ao desenvolvimento de habilidades inerentes à alfabetização científica.

Como estratégia para saber quais elementos deveriam ser considerados como indicativos da ocorrência da alfabetização científica nos alunos, estruturamos, por meio das leituras de Carvalho (2013), Carvalho et al. (1998), Pozo e Crespo (2009) e Campos e Nigro (1999), algumas habilidades, organizadas em categorias, que nos ajudaram, em meio a várias informações, a classificar os dados a serem apresentados e discutidos. Assim, foram elencadas quatro categorias: 
manipulação de variáveis, comunicação de hipóteses, colaboração na resolução de problemas e argumentação.

Nessa perspectiva, vale esclarecer que a técnica da análise categorial funciona como uma "[...] espécie de gavetas ou rubricas significativas que permitem a classificação dos elementos de significação constitutivos da mensagem" (BARDIN, 2011, p. 43). Desse modo, separamos em categorias a totalidade de alguns dados levantados nos principais textos estudados, ou seja, separamos unidades que serviram como critérios de classificação ou códigos facilitadores para decodificar os dados coletados em suas unidades de sentido e significação. Assim, agrupamos algumas unidades de significação de mesma ordem e entendimento em respectivas correspondências categoriais.

Guiados por essa técnica, procuramos sistematicamente, por meio de uma leitura atenta, verificar na fala e na escrita dos pesquisados a presença dos elementos estruturados nas categorias. Após esse procedimento, transcrevemos as ideias dos alunos e fizemos a devida análise.

\section{APRESENTAC̣ÃO E ANÁLISE DOS DADOS}

Como já fora mencionado, para a análise dos dados da presente pesquisa tomamos como referência a sequência didática "De onde vem o arco-1́ris?". Primeiro, fizemos a transcrição e a análise do discurso de algumas falas produzidas no decorrer da aula, depois, fizemos o levantamento de algumas categorias que nos ajudaram a melhor sintetizar os resultados da presente pesquisa. Utilizamos a letra "A" acompanhada de números aleatórios para nos referir aos sujeitos pesquisados e à pesquisadora utilizamos a letra "P".

As falas coletadas pela gravação foram mantidas na íntegra, já os dados coletados por meio da escrita foram corrigidos ortograficamente, deixando à mostra somente os erros gramaticais, de coerência e coesão. Assim, vejamos a transcrição de algumas partes da aula com respectivas análises.

P: Vamos prestar atenção! Por que o arco-íris aparece no céu?

A1: É porque quando chove, daí quando faz sol o arco-íris aparece!

A2: No DVD que eu assisti, é é é... mostrava que quando chove, ai depois quando aparece o sol forma o arco-íris.

De acordo com Carvalho et al. (1988), a desvinculação das concepções que os alunos aprendem no cotidiano não é um processo simples, mas uma alternativa é o professor tentar mudar a cultura experimental, criando caminhos para que o aluno passe de uma experimentação espontânea a uma experimentação científica. De acordo com Campos e Nigro (1999), para que essa passagem aconteça satisfatoriamente, o professor deve não somente ensinar conceitos, mas, também, ensinar procedimentos e atitudes, pois tais conteúdos encaminham os alunos para maneiras diferentes de se relacionar com o objeto de estudo.

"Propondo o problema" foi o momento da aula em que o material 
experimental foi apresentado aos alunos. Nesse intento, vale explicitar que o problema não pode ser uma questão qualquer. Ele deve ser interessante, de modo que estimule o aluno a se aventurar em uma investigação, colocando em prática ações e raciocínios necessários ao desenvolvimento intelectual (CARVALHO, 2013). Vejamos o trecho da aula em que realizamos essa etapa:

P: Crianças, venham aqui pra frente que agora iremos realizar uma atividade prática, um experimento! (Os alunos se levantam das cadeiras, muito barulho é feito nessa hora.)

P: Psiu... pronto? Vamos prestar atenção! O que temos aqui?

A: Uma lanterna e uma vasilha com água. (Resposta geral da turma.)

P: Certo, então como fazer para uma imagem do arco-íris aparecer no quadro branco usando esses materiais?

Após a apresentação do problema, foi realizada a etapa da sequência "Agindo sobre os objetos para ver como eles reagem". Foram apresentadas as seguintes falas:

P: Psiu... Pessoal, o que combinamos? Combinamos que temos que esperar a vez do outro falar. Quando for falar levanta a mão, certo?

A: Certo! (Resposta geral da turma.)

P: Então presta atenção! Como fazer aparecer a imagem de um arco-íris no quadro branco usando a lanterna e essa bacia com água?

A4: A luz clareia a água.

P: Certo, olha a pergunta: a gente tem que fazer como para fazer a imagem do arco-íris aparecer no quadro branco usando esses materiais?

A5: Colocar a lanterna assim. (Aluno aponta a lanterna para vasilha.)

A6: Refletir a luz na água.

P: Ligada ou desligada?

A: Ligada. (Resposta geral da turma.)

P: Então deixe eu fazer. Vamos ver. O que eu faço?

A7: Bota aqui! (O aluno aponta a mão para a vasilha com água, mais especificamente para o lado direito da vasilha.)

(Pesquisadora direciona a lanterna ligada ao lado da vasilha.)

P: E aí conseguimos resolver o problema?

A: Não... (Resposta geral da turma.)

A8: Só tô vendo a luz da lanterna.

(Risos.)

Pelo relato acima, fica explícita a ideia de que os alunos apresentaram uma empatia pela atividade, pois, tão logo explanada a situação a ser resolvida, se aventuraram a lançar hipóteses a fim de resolver o problema. Esse comportamento afetivo com a atividade é um quesito essencial para aprendizagem, pois, de acordo com Selbach (2010), para que o aluno aprenda ciências, é necessário que o professor trabalhe com proposições que envolvam não somente atributos cognitivos, mas também aspectos afetivos e emocio- 
nais. Ademais, esse momento é uma oportunidade excelente para ensinar conteúdos atitudinais, como: espírito coletivo, cooperação e respeito pela opinião do outro.

Interferindo em situações, opinando em discussões e emitindo juízo de valor acerca de resultados controversos, os alunos conseguiram encontrar uma ação que convergiu ao efeito desejado. Contudo, esse efeito não aconteceu na primeira tentativa. Falas dos alunos A10 e A11 revelam isso: "Coloca a lanterna no meio e um pouco longe da vasilha" (A10); "Faz assim, pega a lanterna e aponta para boca da vasilha" (A11). Vejamos o momento em que os alunos conseguiram encontrar uma solução para o problema:

A12: Professora, coloca a lanterna aqui apontando no meio da água!

P: Tá certo! Assim? (Professora faz a ação solicitada pelo aluno.)

A: É... (Resposta geral da turma.)

A: Ali, olha ali! O arco-íris! (Eufóricos.)

O sentimento de prazer e satisfação dos alunos ao resolverem o problema foi claro. Foi certo que os alunos, antes de chegar à resolução do problema, se aventuraram em muitas hipóteses que se mostraram ao final inadequadas. Contudo, Carvalho (2013) nos diz que hipóteses que convergem ao "erro" são essenciais para a construção do conhecimento, pois se tratam de momentos ricos em aprendizagem de procedimentos e práticas de investigação.

Resolvido o problema, passamos para o momento "Tomando consciência de como foi produzido o efeito desejado". Com as cadeiras da sala de aula organizadas no formato de um círculo, a pesquisadora iniciou a discussão:

P: Vamos agora conversar um pouco sobre o que a gente fez. Olhe só, eu agora vou fazer umas perguntas pra gente pensar no que a gente fez. Eu quero que vocês pensem e me digam como, como a gente fez pra fazer a imagem do arco-íris aparecer no quadro?

(Os alunos falam todos de uma vez.)

P: Nós vamos escutar um de cada vez. Psiu... Vamos lá? Certo?

A: Certo! (Resposta geral da turma.)

P: Quem vai começar?

A6: Eu! A gente pegou a lanterna, aí colocou do lado da vasilha com água, daí aquele reflexo passou e colocou o arco-íris.

P: Passou aonde?

A6: Passou na bacia e atravessou a água e fez o arco-íris.

P: Mais alguém quer falar?

A10: Aqui! Aqui! Eu, eu, eu!

P: Certo, como foi?

A10: A senhora pegou uma bacia, aí mandou colocar água, aí colocou uma lanterna ligada no lado da bacia, aí primeiro colocou a luz da lanterna pra baixo, a luz sumiu... depois o A10 pediu pra colocar mais pra cima a luz da lanterna, a luz apareceu no quadro... depois a senhora colocou no meio da bacia, daí a luz passou por 
dentro da bacia, daí a água fez aparecer o arco-íris.

P: Quem mais quer falar?

A13: Colocava a lanterna mais perto, mais pra baixo, daí a luz passava pela água e a água fazia aparecer um monte de cores. O A11 pediu pra colocar a lanterna um pouco pra baixo e um pouco longe da bacia, daí o arco-íris ficava grande... quando colocava perto ficava pequeno e bem forte.

Podemos dizer que esse momento da aula foi um espaço em que os alunos realmente passaram da ação manipulativa para a intelectual. Assim, os estudantes desenvolveram raciocínios para explicar o que fizeram na atividade. De tal modo, tomaram consciência de suas ações. Vale ressaltar, também, que foi um momento em que os alunos desenvolveram uma habilidade bastante importante na construção do conhecimento científico, que é o saber comunicar procedimentos de forma organizada.

Além disso, também é notório que os alunos apresentaram um espírito bastante colaborativo ao escutar a fala do outro. Tal atitude é importante, pois ao fazer isso "[...] o aluno não só relembra o que fez, como também colabora na construção do conhecimento que está sendo sistematizado" (CARVALHO, 2013, p. 12). causais":

Vejamos agora alguns trechos do momento "Elaborando explicações

P: Por que quando a gente pega uma bacia com água e coloca uma lanterna ligada ao lado dela aparece a imagem do arco-íris?

(Por alguns minutos os alunos permaneceram em silêncio.)

P: Alguém quer dizer?

(Risos.)

A14: A gente apontou a luz da lanterna na água e a água fez a luz da lanterna aparecer colorida, daí apareceu o arco-íris lá.

A8: Eu sei uma pessoa que sabe explicar, mas tem vergonha.

(Risos.)

P: Se a gente tirar a água da bacia e colocar a luz da lanterna aqui (pesquisadora aponta a lanterna para vasilha) aparece a imagem do arco-íris?

A: Não! (Resposta geral da turma.)

P: Por que não?

A15: Por que senão não vai refletir a luz do arco-íris.

P: Por quê?

A15: Por que é a água que faz o colorido!

P: Certo, mas como a água faz o colorido?

A17: A luz branca reflete na água, daí ela, ela se separa nas cores que a gente viu.

P: Alguém mais quer falar por que o arco-íris apareceu?

A9: A luz branca da lanterna vinha assim (aluno faz gesto com a mão no sentido de mostrar a luz penetrando na água) daí quando ela chegou na água atravessou ela e refletiu a luz separada, vermelho, amarelo, laranja...

Percebe-se, no diálogo, que houve um silêncio inicial quando a pes- 
quisadora fez a pergunta que levaria à explicação causal do fenômeno. Por esse motivo, como forma de oferecer subsídios ao desenvolvimento do raciocínio dos alunos, a pesquisadora refez o questionamento: "Se a gente tirar a água da bacia e colocar a luz da lanterna aqui aparece a imagem do arco-íris?" Desse modo, algumas explicações, mesmo que tímidas, começaram a aparecer. Vejamos algumas delas.

A10: A luz da lanterna passa pela água, quando passa pela água a luz da lanterna vira várias cores: vermelho, laranja, azul, azul claro, violeta, amarelo. Oh tia, meu pai tava lavando o carro aí a gente viu o arco-íris.

P: O que seu pai fez pra isso acontecer?

A10: Ele pegou a mangueira, apertou pra sair água e jogava a água pra cima a gente via todas as cores.

P: Quando isso aconteceu o dia estava ensolarado? Era um dia de sol?

A10: Tava.

P: Por que será que o arco-íris apareceu nessa situação?

A7: Eu sei, deixa eu dizer!

P: Certo, diga!

A10: Eu acho que é por que quando a luz do sol entra nos pingos de água se reflete do lado de fora de várias cores.

P: Sei...

Essas falas revelam que os alunos, por meio do diálogo, aos poucos foram aprimorando suas explicações, falas como a do A17 nos revelam isso: "Por que a luz da lanterna bateu na vasilha com água... quando entrou na água se transformou em várias cores e quando as cores reflete para o lado de fora da água, a gente vê o colorido das cores." É notório também que o A10 buscou uma situação cotidiana para apoiar seu argumento. Esse fato revela que o conteúdo abordado não é algo fora da realidade dos alunos. Essa questão é bastante importante para o processo de aprendizagem, pois o professor deve escolher assuntos que façam parte do mundo físico da criança, de modo que ela possa progressivamente desenvolver os primeiros significados da cultura científica e, assim, ter um entendimento coerente sobre o mundo (CARVALHO et al., 1998).

Dando continuidade à pesquisa, trabalhamos com o vídeo "De onde vem o arco-íris?", bem como com o texto "O segredo do arco-íris". Esses recursos foram aplicados no momento da sequência "Aprofundando o conhecimento". Vejamos as explicações dos alunos após o uso desses recursos didáticos, que foram utilizados como sistematização e contextualização social dos conteúdos. Vale ressaltar que essas explicações são algumas transcrições retiradas dos questionários trabalhados durante as aulas. A pergunta, basicamente, foi a seguinte: por que conseguimos projetar a imagem do arco-íris no quadro? 
Ensino de ciências por investigação: uma estratégia pedagógica para promoção da alfabetização científica nos primeiros anos do ensino fundamental

Quadro 3 - Explicações dos participantes após a atividade de sistematização e contextualização social do conteúdo

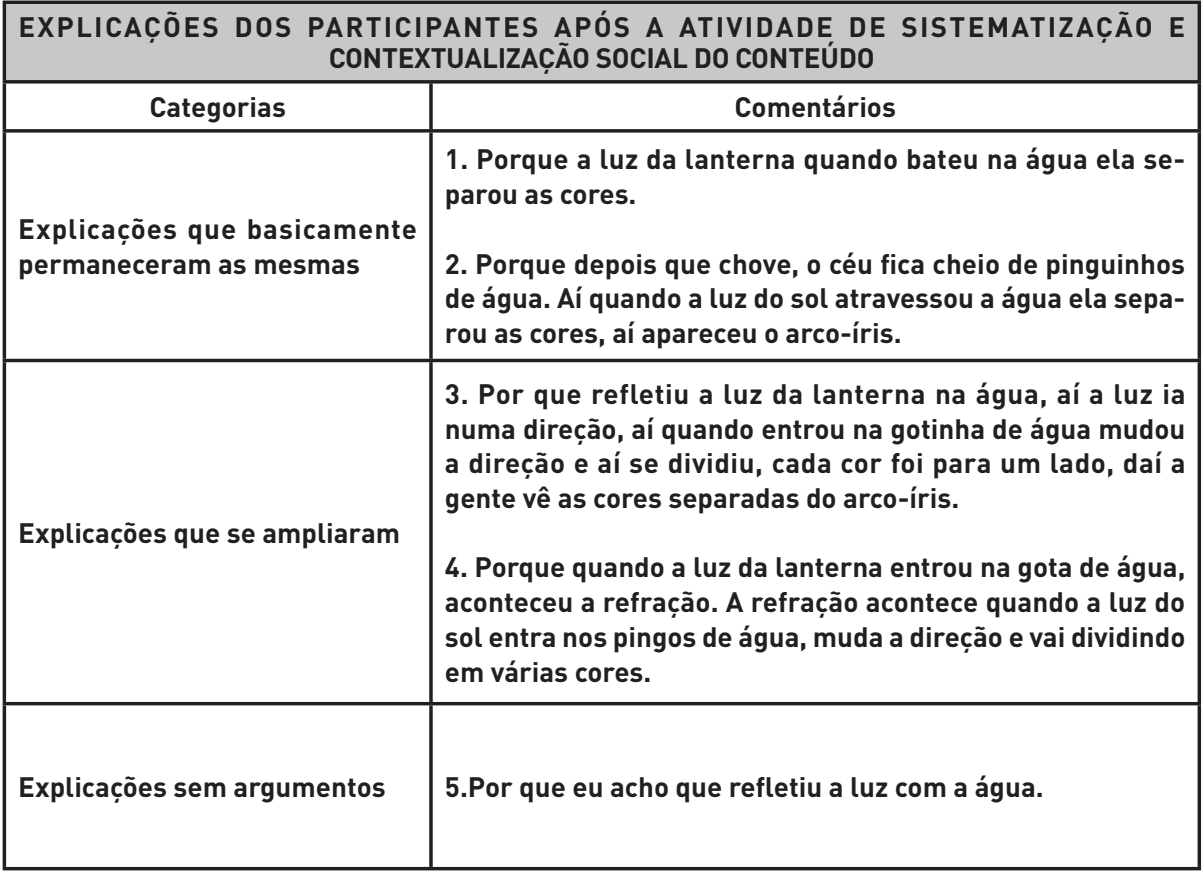

Fonte: Dados da pesquisa.

Percebe-se que o trabalho com o texto o "Segredo do arco-íris", bem como com o vídeo "De onde vem o arco-íris?", foi rico para a aprendizagem, pois ficou evidenciado no quinto momento da sequência didática, "Dando explicações causais", que os alunos, por meio da reflexão das variáveis manipuladas, pela argumentação, e também pela socialização de ideias no grupo, significaram de forma coerente a ocorrência do arco-íris.

Também ficou claro que os alunos puderam desenvolver novos raciocínios que aprimoraram a compreensão do fenômeno. Uma prova de tal fato foi que, após o trabalho com o texto o "Segredo do arco-íris" e o vídeo "De onde vem o arco-íris?", oito alunos passaram a explicar o fenômeno estudado, mesmo que de forma simplificada, pelo conceito de refração. A propósito, cabe destacar que, nessa etapa da sequência didática, quatro alunos não conseguiram desenvolver explicações causais e seis alunos, mesmo com a utilização do vídeo e do texto em questão, continuaram com as mesmas explicações construídas durante a realização do experimento.

Contudo, isso não significa que esses seis alunos não desenvolveram aprendizagens, não se trata disso, pois, como vimos na categoria "Explicações que basicamente permaneceram as mesmas", os alunos compreenderam o fenômeno em linhas mais aproximadas das explicações científicas. Além disso, a aprendizagem não acontece de uma vez só, mas por reorganizações sucessivas que se mate- 
rializam ao passo que interagimos com novos conceitos, com novos materiais de estudo, com novas experiências de vida.

$\mathrm{Na}$ segunda etapa da sequência didática foi trabalhada a "Composição da luz branca." O objetivo foi pontuar um problema capaz de desencadear raciocínios que levassem a criança a compreender que a luz branca é a mistura de várias cores, isto é, o objetivo foi conduzir os alunos a melhor compreender o processo de formação do arco-íris.

Assim, as mesmas etapas do primeiro momento da sequência didática foram vivenciadas, já o material trabalhado foi o experimento que Newton fez em seu quarto com o prisma. Após o término de todas as etapas dessa parte da sequência os alunos apresentaram argumentos da seguinte ordem:

\begin{abstract}
A1: Eu acho que o branco faz as outras cores, porque as outras fazem o branco. A4: Por que o branco é a mistura das cores do arco-íris... Para ver que é verdade, pegue o ventilador, daí você coloca o disco de Newton na hélice do ventilador, aí você liga no três, aí você vai ver que as cores do arco-íris ficam branco... Isso é verdade, eu vi com a tia. Mas tome cuidado, você deve ligar o ventilador no três, por que senão o ventilador gira fraco e a gente não vê as cores bem misturadas, aí a gente não consegue ver o branco. A5: Por que o disco tem várias cores. Acontece porque a cor branca se passar pela água se reflete e se divide em várias cores. Daí, se a gente quiser ver o contrário, só é a gente pegar o disco de Newton e colocar no ventilador e girar bem rápido, tem que colocar no três... Daí acontece que o disco colorido fica branco. Daí é o contrário, o branco vira várias cores e várias cores viram branco.
\end{abstract}

Ficou evidente que essa etapa da aula, em que foi trabalhado o experimento com o disco de Newton, conduziu os alunos a melhor entender o processo de formação do arco-íris. Essa afirmativa vem do fato de os estudantes terem compreendido a ideia de que a luz branca se separa em várias cores e que o inverso também é possível de acontecer, isto é, as várias cores do arco-íris se transformam em branco. Nesse contexto, cabe mencionar que a estratégia de abordar o assunto sob a forma de problema a ser resolvido, por meio de ações próprias da cultura científica - como construção de hipóteses, manipulação de variáveis, argumentação e comunicação de resultados -, contribuiu, sobremaneira, para que os alunos agissem sobre os objetos e adquirissem consciência das suas ações a ponto de entender as causas que convergiram ao efeito desejado.

Acreditamos que esse caminho, que vai desde o conhecimento do problema a ser investigado, passando pelos momentos de manipulação dos objetos, pela aquisição de consciência das ações, até a sistematização de ideias, é uma alternativa que ajuda os alunos a progredir nos conceitos que envolvem a ciência, pois se trata de uma forma de conduzir o aluno a investigar de forma não superficial.

Para apresentar um panorama mais sintético de algumas habilidades avaliadas durante toda a sequência didática, apresentamos logo abaixo algumas categorias ${ }^{4}$ acompanhadas de respectivos exemplos. As informações foram retiradas das gravações realizadas durante as aulas. 
Quadro 4 - Habilidades avaliadas na Sequência de Ensino Investigativa - SEI

\begin{tabular}{|c|c|}
\hline \multicolumn{2}{|c|}{ HABILIDADES AVALIADAS NA SEQUÊNCIA DE ENSINO INVESTIGATIVA - SEI } \\
\hline Categorias & Exemplos \\
\hline Manipulação de variáveis & $\begin{array}{l}\text { A gente tem que clarear a água. } \\
\text { Refletir a luz na água. } \\
\text { Bota a luz mais pra cima. } \\
\text { Professora aponta a lanterna aqui no meio da água. } \\
\text { Coloca a lanterna mais afastada da vasilha. } \\
\text { Tem que colocar o ventilador na tomada. } \\
\text { Coloca aqui na frente. } \\
\text { Tem que tirar. }\end{array}$ \\
\hline Comunicação de hipóteses & $\begin{array}{l}\text { A gente pegou a lanterna, colocou água na vasilha e formou o } \\
\text { arco-íris no quadro. } \\
\text { Colocava a lanterna mais perto, mais pra baixo e um pouco lon- } \\
\text { ge da bacia, daí o arco-íris ficava grande, quando colocava perto } \\
\text { ficava pequeno e bem forte. } \\
\text { Tem que colocar não tão pra cima e não tão pra baixo daí a luz } \\
\text { da lanterna vai poder atravessar a água e fazer o arco íris acon- } \\
\text { tecer. } \\
\text { A gente pegou o ventilador tirou a tampinha da hélice e colocou } \\
\text { o disco de Newton, aí depois a gente colocou a tampinha de vol- } \\
\text { ta, daí foi hora de ligar o ventilador na velocidade máxima e o } \\
\text { disco foi ficando branco. }\end{array}$ \\
\hline $\begin{array}{l}\text { Colaboração na resolução } \\
\text { de problemas }\end{array}$ & $\begin{array}{l}\text { Gira pra esse lado. Vem A10 ajudar! } \\
\text { o A3 pediu pra senhora colocar a lanterna no meio e mais longe } \\
\text { da vasilha. } \\
\text { O A5 e o A6 ajudou a senhora a colocar a tampinha no ventilador. }\end{array}$ \\
\hline Argumentação & $\begin{array}{l}\text { Newton queria provar o contrário. Como o branco fica várias co- } \\
\text { res as várias cores também ficam branco. } \\
0 \text { branco é a mistura de todas as cores que formam o arco-íris. } \\
0 \text { disco tem as várias cores que formam a cor branca, daí quan- } \\
\text { do coloca o disco no ventilador e bota pra girar rápido as várias } \\
\text { cores se misturam daí ficam brancas. }\end{array}$ \\
\hline
\end{tabular}

Fonte: Dados da pesquisa.

\section{CONSIDERAÇÕES FINAIS}

Pelos dados da presente pesquisa, ficou evidenciado que o ensino por investigação é uma metodologia eficiente para os propósitos de alfabetizar cientificamente nossos alunos. Essa assertiva foi se confirmando ao passo que os discentes, 
mediados pelos problemas a serem resolvidos, posicionaram-se como protagonistas ativos na construção da aprendizagem, isto é, os alunos não se constituíram meros observadores da aula do professor. Essa ação permitiu aos discentes aprender conteúdos conceituais pelo exercício da análise crítica.

$\mathrm{O}$ ensino por investigação foi se mostrando uma metodologia adequada à promoção da alfabetização científica, ao passo que os alunos apresentaram uma empatia pelo problema a ser resolvido e, movidos pela curiosidade, desenvolveram habilidades, como: capacidade de manipular variáveis, de questionar evidências, de investigar situações controversas, de organizar dados e comunicar métodos de forma coerente.

A análise dos dados revelou que os alunos, quando convidados a participar de atividades investigativas, desenvolvem seus conhecimentos conceituais de forma compreensiva, o que é muito bom para alfabetização científica. Tal feito foi alcançado por meio das seguintes habilidades apresentadas: pensamento crítico, raciocínio, flexibilidade, argumentação, solução de problemas e síntese.

Ainda ficou evidenciado que o ensino por investigação promove no aluno a autonomia para emitir juízo de valor sobre um determinado assunto. Essa atitude ficou clara a partir do momento em que os alunos, movidos pelo desejo de saber as reações que suas ações ocasionariam nos objetos, interferiram em situações e opinaram em discussões sem medo de errar.

Outra questão, bastante importante para o processo de aprendizagem, foi o ensino de ciências por investigação ter se mostrado como uma metodologia eficiente para trabalhar a questão da cooperação e do consenso entre os alunos. Essas questões foram apresentadas no momento em que os participantes da aula, com entusiasmo, ingressaram em discussões coletivas de forma respeitosa, ou seja, no momento em que souberam escutar a opinião dos seus pares. A cooperação também se mostrou evidente quando os alunos consideraram a importância do pensamento do outro para a resolução do problema.

A análise dos dados também revelou que o ensino de ciências por investigação é uma metodologia adequada para conduzir os alunos a aprender a natureza da ciência de maneira implícita. Esse ponto foi sendo confirmado ao passo que os alunos, diante do problema, delineavam hipóteses, testavam hipóteses, pensavam sobre as evidências, comunicavam os métodos utilizados, concluíam argumentos e discutiam no coletivo as explicações construídas.

Ademais, essa metodologia de ensino revelou ser bastante eficiente no sentido de criar processos mentais para que os alunos passassem do saber espontâneo ao saber conceitual. Essa alegação vem do fato de essa prática de ensino ter propiciado espaço não só para manipulação e observação dos fenômenos, mas também para prerrogativas em que o aluno sai de uma postura passiva e começa a agir sobre seu objeto de estudo.

Destarte, pelo conjunto de dados apresentados e analisados nesta pesquisa, chegamos ao seguinte resultado: o ensino de ciências por investigação se constitui como uma metodologia de ensino adequada para alfabetizar cientificamente alunos dos primeiros anos do Ensino Fundamental, pois, quando convidados a fazer investigações, eles se envolvem ativamente na atividade e passam a desenvolver conteúdos conceituais de forma compreensiva. Tal fato contribui, sobremaneira, 
para que o estudante consiga fazer uma leitura de mundo coerente, ampliando, por isso, seu conhecimento, logo, a sua cultura.

\section{NOTAS}

${ }^{1}$ Esses conhecimentos prévios, no contexto em tela, também são conhecidos na literatura da didática das ciências como conhecimentos alternativos, intuitivos, ou ainda como erros conceituais, pré-conceitos ou ideias prévias.

${ }^{2}$ Essa primeira parte começa no início do filme e termina antes da explicação do experimento de Newton com o prisma (o professor deve dar pausa no vídeo). O objetivo é somente trabalhar a ideia de refração. $\mathrm{Na}$ segunda etapa da sequência, especificamente, no $6^{\circ}$ momento "aprofundando a aprendizagem" será trabalhado o vídeo por completo. O objetivo nesse momento é levar o aluno a aprofundar seu conhecimento no sentido de compreender que a luz branca é a mistura de várias cores.

${ }^{3}$ Essa primeira parte vai desde o início do texto até as discussões referente à refração. Na segunda etapa da sequência, especificamente, no $6^{\circ}$ momento "aprofundando a aprendizagem" será trabalhada a segunda parte do texto que tem início com as discussões referentes à experimentação de Newton com o prisma e vai até o final do texto.

${ }^{4}$ Vale informar que as habilidades postas nas categorias foram construídas pelos autores a partir das leituras dos principais textos que fundamentaram esta pesquisa. Assim, após ler os textos de Carvalho et al. (1998), Carvalho (2013), Pozo e Crespo (2009) e Campos e Nigro (1999), foram agrupadas algumas habilidades inerentes ao ensino por investigação. Logo após, foi feita a leitura de toda a transcrição da aula com o objetivo de classificar falas que representassem as habilidades sugeridas em cada categoria.

\section{REFERÊNCIAS}

BARDIN, Laurence. Análise de conteúdo. São Paulo: Edições 70, 2011.

BRICCIA, Viviane. Sobre a natureza da ciência e o ensino. In: CARVALHO, Anna Maria Pessoa de. Ensino de ciências por investigação: condições para implementação em sala de aula. São Paulo: Cengage Learning, 2013, p. 111-128.

CACHAPUZ, A. et al. A necessária renovação no ensino de ciências. São Paulo: Cortez, 2005.

CAMPOS, Maria Cristina da Cunha; NIGRO, Rogério Gonçalves. Didática de ciências. São Paulo: FTD, 1999

CARVALHO, Anna Maria Pessoa de. Ensino de ciências por investigação: condições para implementação em sala de aula. São Paulo: Cengage Learning, 2013.

CARVALHO, Anna Maria Pessoa de. et al. Ciências no Ensino Fundamental: o conhecimento físico. São Paulo: Scipione, 1998. (Pensamento e Ação no Magistério).

CHASSOT, Attico. Alfabetização científica: questões e desafios para a educação. Rio Grande do Sul: Unijuí, 2000.

DEMO, Pedro. Educação e alfabetização científica. São Paulo: Papirus, 2010. (Papirus Educação). 
LORENZETTI, Leonir; DELIZOICOV, Demétrio. Alfabetização científica no contexto das séries iniciais. 2000. 135 f. Dissertação (Mestrado em Educação na área de Educação em Ciência) - Universidade Federal de Santa Catarina, Florianópolis, 2000. Disponível em: <http://www.portal.fae. ufmg.br/seer/index.php/ensaio/article/

viewFile/35/66>. Acesso em: 2 abr. 2013.

MARCONI, Marina de Andrade; LAKATOS, Eva Maria. Técnicas de pesquisa. 6. ed. São Paulo: Atlas, 2006.

NEVES, José Luis. Pesquisa qualitativa: características, usos e possiblidades. Caderno de pesquisa em administração, São Paulo, v. 1, n. 3, p. 1-5, 2. sem. 1996. Disponível: <http://www.dcoms.unisc. $\mathrm{br} /$ portal/upload/com_arquivo/pesquisa_qualitativa_caracteristicas_usos_e_possibilidades.pdf $>$. Acesso em: 10 jul. 2007.

POZO, Juan Ignacio; CRESPO, Miguel Ángel Gómez. A aprendizagem e o ensino de ciências: do conhecimento cotidiano ao conhecimento científico. 5. ed. Porto Alegre: Artmed, 2009.

SASSERON, Lúcia Helena; CARVALHO, Anna Maria Pessoa de. Almejando a alfabetização científica no Ensino Fundamental: a proposição e a procura de indicadores do processo. Investigações em Ensino de Ciências, Porto Alegre, v. 13(3), n. 3, p. 333-352, dez. 2008. Disponível em: <http://www. if.ufrgs.br/ienci/artigos/Artigo_ID254/v16_n1_a2011.pdf>. Acesso em: 25 jun. 2014.

SASSERON, Lúcia Helena; CARVALHO, Anna Maria Pessoa de. Ensino por CTSA: almejando a alfabetização científica no Ensino Fundamental, 2007. Disponível em: <http://www.nutes.ufrj.br/ abrapec/vienpec/CR2/p487.pdf>. Acesso em: 07 jun. 2014.

SEVERINO, Antônio Joaquim. Metodologia do trabalho científico. 23. ed. São Paulo: Cortez, 2007. SELBACH, Simone. et al. Ciências e didática. Rio de Janeiro: Vozes, 2010. (Como bem ensinar).

SILVA, Márcia Gorete Lima da; SILVA, Antônia Francismar da; BELTRAN NUÑES, Isauro. Dos modelos de mudança conceitual à aprendizagem como pesquisa orientada. In: BELTRAN NUÑES, Isauro; RAMALHO, Betânia Leite (Org.). Fundamentos do ensino: aprendizagem das Ciências Naturais e da Matemática: o novo Ensino Médio. Porto Alegre: Sulina, 2004.

SOARES, Magda. Letramento e Alfabetização: as muitas facetas. Revista Brasileira de Educação, Belo Horizonte (Centro de alfabetização, leitura e escrita - Universidade Federal de Minas Gerais), n. 25, p. 5-17, jan./fev./mar./abr. 2004. Disponível em: < http://www.scielo.br/pdf/rbedu/n25/ n25a01.pdf/>. Acesso em: 8 fev. 2014.

ZIMMERMANN, Erika Maíra. Letramento científico e CTS na formação de professores para o ensino de ciências. In: CONGRESO ENSEÑANZA DE LAS CIENCIAS, 7., 2005. Anais... (número extra). Disponível em: <http://ddd.uab.cat/pub/edlc/edlc_a2005nEXTRA/edlc_a2005nEXTRAp320letcie.pdf>. Acesso em: 6 nov. 2014.

Data do recebimento: 12/08/2015

Data da aprovação: 07/04/2016

Data da Versão final: 19/04/2016

Contato:

Liliane Oliveira de Brito

Endereço do principal autor:

Rua Jardim das Flores, n 150. Bairro Vila Maria. Palmeira dos índios, AL.

CEP: 57607300 